\title{
Reimagining Development through the Crisis Watch Initiative
}

\author{
J. Allister McGregor
}

\begin{abstract}
This article reflects on the experience of the Crisis Watch initiative. This established a network of organisations and individuals who were involved in monitoring and acting on the ongoing effects of the 2008 financial crisis at the grassroots level. It provided a basis for understanding the ongoing human impacts of crisis and for sharing lessons on how to generate evidence quickly for policy consideration. The interplay between the financial crisis and other ongoing crises meant that people often experience a compound crisis. In this context, the attribution of specific impacts to the financial crisis alone is difficult and can lead to inappropriate simplifications for policy. The experience from Crisis Watch urges us to reimagine the relationship between crises and development in terms of a systems approach, which draws on complexity thinking. This focus on relationships between people represents a significantly different starting point for development policy thinking.
\end{abstract}

\section{Introduction}

When news of the financial crisis of 2008 began to break, a group of Research Fellows at IDS mobilised to consider the possible consequences for developing countries. Their deliberations were based on a limited amount of information about the ways that the crisis was unfolding globally; on experience of previous similar crises and on theoretical analyses of how such shocks might play out in developing countries. This resulted in a collection of articles published as an IDS Bulletin entitled 'Policy Responses to the Global Financial Crisis' in January 2009 (Sumner and McGulloch 2009). It was apparent as these discussions proceeded, that there was an absence of real empirical insight into what was happening in different developing countries and how those impacts were affecting poor people in particular. Around this time, a number of IDS researchers, alongside colleagues from the Overseas Development Institute (ODI) and in partnership with developing country partners, were commissioned to carry out grassroots qualitative and quantitative studies of the impacts of the crisis (see Hossain et al. 2010; McCulloch and Grover 2010; ODI 2009, 2010). This was one of a range of initiatives that were being launched at that time by a variety of agencies and organisations to carry out detailed monitoring of the ways that the financial crisis was impacting. In order to generate greater value from these diverse studies, IDS also established an initiative called 'Crisis Watch'.

Crisis Watch was established to coordinate the findings from these various efforts and highlight how they were impacting on human lives. It was anticipated that in addition to the immediate effects of the financial crisis being felt in developing countries at that time, the consequences of the financial crisis would continue to be experienced in waves of secondary impacts over the coming months and years. Crisis Watch formed a network of policy thinkers, academics and activists who were involved in monitoring and acting on the ongoing effects of the 2008 crisis, to share knowledge on frameworks for understanding crisis; methodologies for quickly generating evidence on human impacts and methodologies for designing and implementing policy. ${ }^{1}$

Crisis Watch provided a space within which to discuss and explore the ways in which the crisis was affecting thinking about how we do development and how we might cope with a more volatile and shock-prone future. This article summarises some of the major kinds of reimagining that were stimulated by the Crisis Watch initiative. 


\section{A chronology of crisis watching}

Before we go on to discuss the reimaginings, it is first helpful to consider the chronology of the crisis and the responses of Crisis Watch partners to it. A number of major development organisations were quick off the mark in their efforts to understand the impacts of the financial crisis. For example, the World Bank launched a series of participatory qualitative studies in 15 countries, which were designed to produce rapid information to complement ongoing quantitative work that was already under way (Turk 2009). A number of international NGOs embarked on studies, one being Oxfam who collected insights from 2,500 individuals in 11 case study countries using a variety of methodological approaches (Green et al. 2010). The IDS studies involved using a range of participatory and qualitative research methods in six countries (Hossain et al. 2010). WIEGO (Women in Informal Employment: Globalizing and Organizing) undertook a series of studies focusing particularly on the impacts on women (Horn 2009, 2011). At the same time, a wide range of UN bodies were gathering diverse forms of information on the impacts in particular countries and across particular sectors (Mendoza 2010; WTO/ILO 2009; UNRISD 2009).²

An important landmark in the UN response to the crisis was the establishment of UN GIVAS (Global Impact and Vulnerability Alert System) in July 2009. This initiative was launched by the Secretary General as a major UN response in the wake of the crisis and to establish a body that would convene a global decision support network to provide policymakers with evidence and insight quickly in order for them to take rapid and effective action to protect the vulnerable in response to emerging crises. This initiative was novel because it sought to harness the power of emerging information and communications technologies (ICTs). The new organisation, which was subsequently renamed UN Global Pulse, also had a key role in coordinating the information gathered by a range of institutional partners in the UN family, including UNICEF, UNDP, WHO, WFP, UNFPA, OCHA, as well as the World Bank (see also Hossain, this IDS Bulletin). Drawing on a wide range of material, including that produced by organisations involved in the Crisis Watch network and from a wide range of UN sources, Global Pulse produced their second Voices of the Vulnerable report in 2010 on the human impacts of the crisis (UN Global Pulse 2010). Representatives from Global Pulse and most of the aforementioned organisations took part in the Crisis Watch Workshop at IDS in March 2010, which acted as a forum to stimulate much of this reimagining.

Strangely, however, by mid-2010 there were signs that the steam was beginning to run out of the interest in the crisis in some of the major development organisations. An emergent narrative was building which said that the impacts on developing countries were not as bad as we might have feared and indeed some economies were showing signs of recovery (World Bank 2010). These interpretations increasingly referred to surprising amounts of 'resilience'. As will be argued later in this article, the widespread use of the term 'resilience' can be interpreted as deflecting some of the pressure to reimagine fundamental aspects of development thinking that the financial crisis initially provoked, but it also represents a possible route to some fundamental reimagining.

\section{What we learned about the crisis itself}

Despite this increasingly positive narrative, as the monitoring work of the different organisations got under way, it became apparent that there had been a major global human crisis. Despite the early speculation that some developing countries would not be affected because of their weak integration into the global economy, the studies revealed negative human impacts in most developing (and developed) countries and across a range of different sectors, including those that seemed weakly connected to the global economy. It was also realised that for many people it was a compound crisis in which the effects of the financial crisis were interacting with the ongoing crises generated by high food and fuel prices. In some cases, it was further compounded by other more 'local' crises, including ongoing political and environmental instabilities.

From the qualitative studies that were conducted by organisations involved in the Crisis Watch network during the first year of the crisis, there are two particular kinds of responses that command attention in the context of this reimagining. The first was where poor people effectively retorted, 'which crisis are you referring to?' Their experience is a life which was in chronic crisis and where they found it 
difficult to discern any worsening of their situation as a result of a global financial turmoil. While these responses may or not have been accurate (it is possible that aspects of the 'Triple F' crisis had in fact worsened their plight), they nevertheless highlight that for many people in developing countries, the state of 'crisis' is their everyday condition. It is more a consequence of their structural position in particular societies and then in the global order, than it is a result of any one global or local event.

The second form of response was from those who held the view that this crisis had not had any particular impact on their country. It was heralded that this was a crisis for the North and for the developed world but not for developing countries. This finding was found in a number of the Crisis Watch studies and is echoed in other articles in this IDS Bulletin (Shankland for Brazil; Mehta for India; Habermann for Ethiopia). This type of response appears to have been driven by two possibilities: that the respondents genuinely had seen no evidence of any impact, or that it was an ideological position which was a bravura assertion of autonomy and increased independence from the developed world. In most cases, it was likely a combination of the two. Although the assertion of 'no impact', was understandable in economies that were particularly vibrant and growing, research by Crisis Watch participant organisations in those countries often revealed some impacts, but these were restricted to some sections of the populations, in some parts of the country (e.g. Times of India, February 2010). The Crisis Watch studies revealed that the global crisis tended to impact on particular and already vulnerable groups. Migrant workers and young people bore the brunt of formal job losses and the elderly and children suffered from knock-on effects on household budgets and coping systems. This had further effects in terms of increasing tensions in communities and additional burdens being placed on informal sector income earning. Families coped with reduced incomes by reducing the quantity and or quality of food consumed. Overall, various reports suggest that the burden of coping with the effects of the crises fell particularly on women in their social reproduction roles of caring for and raising children and ensuring the family was fed adequately (Oxfam 2009). In many locations, this additional burden was reported as having placed great strain on relations with others both within the family and the community. These kinds of impacts which exacerbate marginalisation and polarisation in societies, which destroy aspirations and feed disaffection, and which increase stress and have negative impacts on the relationships that are fundamental to human wellbeing, are not usually captured by the economic data that tell us that the impacts of the global crisis were not as bad as we might have feared.

So what do these two types of responses tell us about reimagining development in times of crisis? The first reminds us of what social psychologists have called the 'focusing illusion', which is where external observers see a problem but where for those involved, it is just normal life. In such circumstances, the possibilities of a global crisis stimulating an opportunity to reimagine among those being impacted are limited, because from their perspective 'crisis' is a chronic condition. The second set of comments indicates that some people are so far removed from the human impacts of crisis that they are prepared to deny that it has had an effect at all and thus it provides no stimulus for reimagining. This has wider implications, since the failure to communicate information about crisis impacts either within nation-states or globally or even the obfuscation of information about the human impacts of a major global crisis, reduces the pressure nationally and globally for reimagining. These processes allude to the politics and power that are in play in the production and dissemination of evidence about crisis impacts.

\section{What we learned about the methodologies for understanding the human impacts of crises}

While there are masses of data generated on many aspects of the condition of developing countries, very little of it is produced quickly. In a contribution to the debate on the financial crisis in the New York Times, Paul Krugman reminded us that Keynes once sagely observed at the time of the Great Depression that, 'In the long run we are all dead'. To modify this provocatively and inelegantly, regarding crises, by the time the quantitative data is produced to confirm what the impacts of the particular crisis have been, some people might be dead. A specific purpose for the organisations involved in the Crisis Watch network was to be timely in the generation of data on the impacts on people located in different 
places in the global economy. The monitoring tools and systems that were developed by the network organisations prioritised the quick production of data that would be accessible for policymakers and decision-makers. The methodologies employed were designed with this as a foremost consideration and as such, involved trade-offs between rapid delivery for policy relevance and scientific rigour.

The work of Crisis Watch network organisations has shown that it is possible to generate data quickly that effectively identifies emerging trends and generates detailed insights into the complex processes around crisis impacts. But getting this data taken seriously is another matter. Generating this kind of data quickly involves compromises in respect of key social science methodological considerations. There are serious challenges in both the representativeness and replicability of such studies. Usually, both of these problems for social science studies are dealt with by sampling strategies which are statistically defensible. However, the type of studies that were required here and the scale of funding for them, did not permit sampling on the scale that would be required to construct a statistical defence of the data. The purposive, opportunistic and small-scale nature of the studies provide a route to undermine the credibility of the findings. As members of the network discussed during the Crisis Watch workshop, the sampling bias problem is captured in the simple allegation that 'if you go looking for problems, then you will find them'.

We know that there were winners in the financial crisis but the purpose of the Crisis Watch organisations was not to explore who was winning but to find those who were losing and how this was manifesting itself. Moreover, the findings have been remarkably consistent across the different studies and where statistical rigour has not been possible, the careful triangulation of results from different methods generates a form of affirmation for the findings. The studies systematically brought the voices, views and experiences of those affected by the crisis events into the policy discussion. They also affirmed more casual observations from development professionals in a wide range of country locations, that the impacts were significant but were different for different groups in society. So, while the data that was generated did not pretend to have statistical validity, it did have 'face validity': i.e. regardless of whether it was amenable statistical testing or not, for many people it offered insights that rang true with their observations of reality (UN Global Pulse 2010).

Reflecting on the Crisis Watch methodology, discussions suggest that there is a need for reimagining around issues of data, methods and evidence for effective and timely development policy responses. Development policymakers face the question as to what it is they regard as constituting 'evidence' and must confront the conundrum of requiring fast and insightful information about emergent events for smart policy responses and then express concern over the validity of the findings. The alternative is to wait for what is regarded to be statistically valid data to emerge from standard, 'rigorous' and usually quantitatively dominated research processes. In the case of the global financial crisis of 2008, some years later we are still waiting for an abundance of such data and the lives of people who have been affected move on and the moment for effective policy responses may have passed. At a broader level, a subtle process of the discounting of qualitative data by more quantitative-oriented agencies and analysts, in favour of what the hard, quantitative, macrodata could tell us, has served to gradually erode the overall sense of urgency for a broader reimagining of development.

\section{What has the Crisis Watch taught us about what might need reimagining in the development model?}

To conclude this discussion, we can focus on two concepts that came to the fore in discussions during the Crisis Watch process. These highlight two kinds of reimagining development that might be required. The two concepts are: 'attribution' and 'resilience'.

The question repeatedly posed during Crisis Watch discussions was: 'What impacts can we specifically attribute to the global financial crisis?' This was regarded as important for policy thinking, since if a specific channel or set of channels for adverse impacts could be identified, then it might be possible to argue for and design specific policy instruments to protect poor and vulnerable people against these. However, the Crisis Watch studies have tended to report that households and individuals in developing 
countries experienced the effects of the financial crisis as an element of a complex crisis, where combinations of effects from different crisis dynamics interacted in particular social and economic contexts to produce specific adverse outcomes.

Mayoux and Chambers (2005) point out that attributing impacts involves simplifying assumptions about complex and hidden chains of multiple causality and assumptions about directions of causation. While the untangling of complex 'webs of causation' is standard business for macro-level and more highly aggregated forms of study, the translation of this logic to human-level assessment is more problematic. Differentiated impacts, differentiated capacities to cope and differentiated responses are all significant when thinking about real world policy options and design.

When examining the impacts of the global financial crisis from the perspective of those that we see as being affected, a linear notion of attribution looks less credible. A critical appraisal of the notion of attribution in the context of complex crises suggests that one aspect of reimagining development in a more crisis-prone and unpredictable world is to embrace the notion of complexity. When exploring the possible contribution of complexity thinking to development, Ramalingam et al. (2008) argue that the nature of human systems includes feedback processes between interconnected elements and dimensions, which lead to dynamic, non-linear and unpredictable change. As such, the relationships between the global financial crisis and household vulnerabilities cannot easily be dissected. It does not make good policy sense to seek to simplistically assign impacts to neat policy categories, which can then be dealt with by discrete policy instruments. Rather, a systems approach is required, in which the system that is generating poverty and vulnerability outcomes is a coherent entity that comprises multiple and complex interrelationships between elements of the systems in which the individuals and households are involved.

However, some elements of 'complexity thinking' have begun to seep into development thinking and this has been accelerated by the rise to prominence of the notion of 'resilience' in the financial crisis literature. 'Resilience' is a term which has deep roots in complexity thinking and in this context, can be understood as the idea that people, organisations (like businesses) and societal institutions have the flexibility and resources to enable them to cope with shocks and changes to their working environment and can adapt in ways that do not permanently damage them.

But there are mismatches and problems in the way that the term resilience has been used in the literature on the financial crisis. In particular, some reports that heralded the resilience of certain national economies focused on macroeconomic indicators (IMF 2010), while the various Crisis Watch reports indicate profound damage to some members of those societies. Taking a systems perspective, it is apparent that what is called the resilience of the national economic system has come at the cost of the resilience of other parts of the system. For example, the loss of formal employment and the deterioration of formal employment conditions have been characteristics of recent crisis impacts, but the flexible labour laws that have enabled such changes have been important in maintaining economic system resilience. In this crisis period in South-east Asia (compared with the crisis of 1997, for example) fewer businesses have gone bust, thus retaining, for the economic system, the ability to generate future profits, incomes and provide jobs. This level of resilience, however, has been achieved at the cost of those who have been laid off, work part time or have had their real incomes cut. In this case, economic system resilience has not been without its human costs.

The use of the term 'resilience' when referring only to indicators of macroeconomic performance, highlights the fact that conventional macroeconomic measures presently miss much of the informal economy and all of the unpaid work that makes up household 'resilience'. It does not reflect the many gender- and age-differentiated impacts and much of the lasting social damage to people's wellbeing and societies. Findings from Crisis Watch studies on the ground suggest that the resilience of national economies, praised by many observers, is fuelled in large part by the coping strategies of households, and that this coping did not come without a cost. In other words, it does not describe system resilience.

As such, there is a danger that the term 'resilience' has been used in a superficial and 
misleading way. It currently may serve to hide more than it reveals and if its use remains superficial, then it is at risk of becoming merely another development fad that commands attention and resources fleetingly but is never deepened in ways that might require changes in how we think about and do development.

The alternative is to take a more relational understanding of resilience, grounded in the complexity theory. This must be understood primarily in terms of human outcomes and be analysed in terms of the ability of people and communities to withstand and recover from stresses, such as environmental change or social, economic or political upheaval. A resilient society is one that protects its people; that has the capacity to withstand shocks and surprises and, if damaged, is able to rebuild itself, relying on the underpinning psychological foundations of and interlinkages within the system.

The big leap of development imagination required by this approach is to conceive of

\section{Notes}

1 Crisis Watch was funded first by IDS internal funds, through the Reimagining Development initiative and was supported by the voluntary contributions of various IDS staff. It received additional funding from the UK Department for International Development (DFID), primarily to hold a workshop, which brought together the various major organisations to

\section{References}

Deneulin, S. and McGregor, J.A. (2010) 'The Capability Approach and the Politics of a Social Conception of Wellbeing', European Journal of Social Theory 13.4: 501-19

Green, D.; King, R. and Miller-Dawkins, M. (2010) The Global Economic Crisis and Developing Countries: Impact and Response, Oxfam Research Report, Oxfam: Oxford

Horn, Z.E. (2011) Coping with Crises: Lingering Recession, Rising Inflation, and the Informal Workforce, Inclusive Cities Project Report: Women in Informal Employment: Globalizing and Organizing (WIEGO)

Horn, Z.E. (2009) No Cushion to Fall Back On: The Global Economic Crisis and Informal Workers, Inclusive Cities Project Report: Women in Informal Employment: Globalizing and Organizing (WIEGO) societies and economies in terms of the human relationships that comprise them. The turn to a conception of development that focuses on relationships between people provides an alternative starting point for thinking about development policy (McGregor and Sumner 2010). In particular, it moves us beyond thinking about resilience only in terms of building individual or household wealth and capitals and it indicates that we must understand resilience as being an outcome of relationships between individuals and households, in particular social and cultural contexts and under specific political economy conditions. This suggests that efforts by policy to build resilience cannot rely on analysis that focuses only on some dimensions of the system (e.g. economic), rather it must focus on promoting both human wellbeing and the societal institutions that enable us to live well together (Deneulin and McGregor 2010). To do this requires coordinated work across dimensions and at different levels of human social systems, from the individual, to households, up to the levels of nation-state and global order.

reflect on their findings, methodology and on what the crisis was telling us.

2 For a description of the methodologies employed in the different studies, see the reports cited here and in the Crisis Watch Annotated Bibliography at: www.ids.ac.uk/ go/research-teams/vulnerability-and-povertyreduction-team/centre-for-social-protection/ crisis-watch/resources/.

Hossain, N.; Fillaili, R.; Lubaale, G.; Mulumbi, M.; Rashid, M. and Tadros, M. (2010) The Social Impacts of Crisis: Findings from Communitylevel Research in Five Developing Countries, Brighton: IDS

IMF (2010) World Economic Outlook: Rebalancing Growth, Washington DC: International Monetary Fund

Mayoux, L. and Chambers, R. (2005) 'Reversing the Paradigm: Quantification, Participatory Methods and Pro-poor Impact Assessment', Journal of International Development 17: 271-98

McGulloch, N. and Grover, A. (2010) Estimating the National Impact of the Financial Crisis in Indonesia by Combining a Rapid Qualitative Study with Nationally Representative Surveys, IDS Working Paper 346, Brighton: IDS

McGregor, J.A. and Sumner, A. (2010) 'Beyond Business as Usual: What Might 3-D Wellbeing 
Contribute to MDG Momentum?', IDS

Bulletin 41.1: 104-12

Mendoza, R. (2010) Inclusive Crises, Exclusive Recoveries, and Policies to Prevent a Double Whammy for the Poor, UNICEF, Social and Economic Working Paper, May

ODI (2010) The Global Financial Crisis and Developing Countries: Phase 2 Synthesis, ODI Working Paper 316, London: Overseas Development Institute, www.odi.org.uk/ resources/download/4784.pdf (accessed 23 June 2011)

ODI (2009) The Global Financial Crisis and Developing Countries: Preliminary Synthesis of Ten Draft Country Reports, ODI Working Paper 306, London: Overseas Development Institute, www.odi.org.uk/resources/download/3413.pdf (accessed 23 June 2011)

Oxfam (2009) Women Paying the Price: The Impact of the Global Financial Crisis in Southeast Asia, Oxford: Oxfam

Ramalingam, B. and Jones, H. with Reba, T. and Young, J. (2008) Exploring the Science of Complexity: Ideas and Implications for Development and Humanitarian Efforts, ODI Working Paper 285, London: Overseas Development Institute

Sumner, A. and McGulloch, N. (eds) (2009)

'Policy Responses to the Global Financial

Crisis', IDS Bulletin 40.1: 101-8
Times of India (2010) 'No Financial Crisis Impact? India's Poor Grew by 34 Million', February, http://articles.timesofindia.indiatimes.com/ 2010-02-10/india/28125594_1_india-s-gdpindian-growth-financial-crisis (accessed 23 June 2011)

Turk, C. (2009) 'Rapid, Qualitative Assessments of the Impacts of the Economic Crisis: Overview of Findings from Eight Countries', draft report, Washington DC: World Bank

UN Global Pulse (2010) Voices of the Vulnerable: Recovery from the Ground Up, Second Annual Report by UN Global Pulse, www.unglobalpulse.org/voices-report (accessed 23 June 2011)

UNRISD (2009) Social and Political Dimensions of the Global Crisis: Implications for Developing Countries, Report of the UNRISD Conference 12-13 November 2009, Geneva

World Bank (2010) Global Economic Prospects: Crisis, Finance and Growth, Washington DG: World Bank

WTO/ILO (2009) Globalization and Informal Jobs in Developing Countries, Geneva: World Trade Organization/International Labour Organization 